Provided for non-commercial research and education use. Not for reproduction, distribution or commercial use.

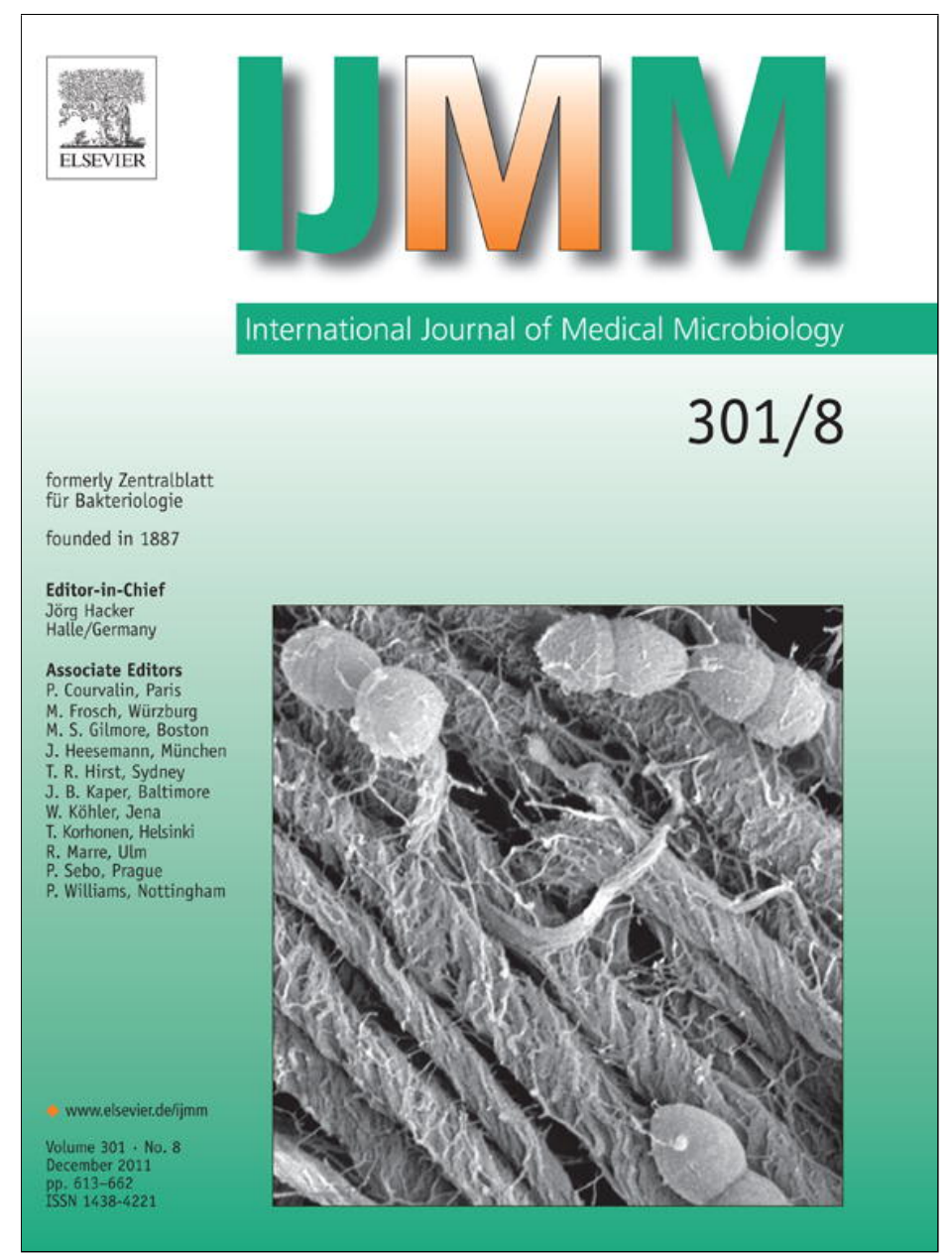

This article appeared in a journal published by Elsevier. The attached copy is furnished to the author for internal non-commercial research and education use, including for instruction at the authors institution and sharing with colleagues.

Other uses, including reproduction and distribution, or selling or licensing copies, or posting to personal, institutional or third party websites are prohibited.

In most cases authors are permitted to post their version of the article (e.g. in Word or Tex form) to their personal website or institutional repository. Authors requiring further information regarding Elsevier's archiving and manuscript policies are encouraged to visit:

http://www.elsevier.com/copyright 
Mini Review

\title{
Livestock-associated methicillin-resistant Staphylococcus aureus in animals and humans
}

\author{
Haitske Graveland $^{\mathrm{a}, \mathrm{b}}$, Birgitta Duim ${ }^{\mathrm{b}}$, Engeline van Duijkeren ${ }^{\mathrm{b}}$, Dick Heederik ${ }^{\mathrm{a}, \mathrm{d}}$, Jaap A. Wagenaar ${ }^{\mathrm{b}, \mathrm{c}, *}$ \\ a Institute for Risk Assessment Sciences, Division Environmental Epidemiology, Utrecht University, P.O. Box 80.176, 3508 TD Utrecht, The Netherlands \\ ${ }^{\mathrm{b}}$ Department of Infectious Diseases and Immunology, Faculty of Veterinary Medicine, Utrecht University, P.O. Box 80.165, 3508 TD Utrecht, The Netherlands \\ ${ }^{c}$ Central Veterinary Institute of Wageningen UR, P.O. Box 65, 8200 AB Lelystad, The Netherlands \\ d Julius Center for Health Sciences and Primary Care, University Medical Center, P.O. Box 85500, 3508 GA Utrecht, The Netherlands
}

\section{A R T I C L E I N F O}

\section{Keywords:}

MRSA

ST398

Livestock

Humans

\begin{abstract}
A B S T R A C T
Since 2004 MRSA emerged in animals, particularly in pigs and veal calves. This new MRSA variant was since its first appearance referred to as Livestock Associated-MRSA (LA-MRSA). In Europe and Northern America, LA-MRSA belongs predominantly to clonal complex (CC) 398 whereas in Asia ST9 seems to be dominant in pigs. Persons in direct contact with LA-MRSA-positive animals have an increased risk of becoming MRSA positive. The risk of carriage is mainly related with the intensity of animal contact and with MRSA prevalence among animals on the farm. In contrast with its success in animals, it seemed that MRSA CC398 is a poor persistent colonizer in humans. MRSA ST398 can, however, cause serious (invasive) infections and outbreaks, although, only incidentally reported so far. Farm hygiene and antimicrobial use contributed to MRSA occurrence in animals. Therefore these two determinants should in principle be incorporated into MRSA-control programmes in animal production. Like any other microorganism, LAMRSA is expected to be able to adapt to new hosts and may change over time in the potential to colonize and to produce toxins. Also, the current circulating clone CC398 may be replaced by another clone in Western countries or emerge in countries where this clone is currently low-prevalent. Ongoing MRSA surveillance in humans and animals is needed to detect changes in epidemiology and to implement effective control measures.
\end{abstract}

(C) 2011 Elsevier GmbH. All rights reserved.

\section{Introduction}

Staphylococcus aureus (S. aureus) is a Gram-positive bacterium which belongs to the commensal flora of humans and various animal species (Vanderhaeghen et al., 2010b). Multiple body sites can be colonized in humans, but the anterior nares are the most frequent colonized sites (Wertheim et al., 2005). Approximately $20 \%$ of healthy human individuals are persistent $S$. aureus carriers, about $30 \%$ are intermittent carriers and around 50\% are never colonized with S. aureus (Kluytmans and Struelens, 2009). In humans, S. aureus is regarded the most important cause of nosocomial infections with clinical conditions ranging from minor skin infections to severe, life-threatening infections (Lowy, 1998; Kluytmans and Struelens, 2009).

In animals, S. aureus is one of the three major pathogenic Staphylococcus species, together with S. hyicus and the Staphylococcus

\footnotetext{
* Corresponding author at: Department of Infectious Diseases and Immunology, Faculty of Veterinary Medicine, Utrecht University, P.O. Box 80.165, 3508 TD Utrecht, The Netherlands. Tel.: +31302534376.

E-mail address: j.wagenaar@uu.nl (J.A. Wagenaar).
}

intermedius group - SIG (S. pseudintermedius, S. intermedius, and S. delphini) with S. hyicus and SIG more restricted in host species compared to S. aureus. S. aureus can cause intramammary infections in cattle and small ruminants (Vanderhaeghen et al., 2010b). It can also cause joint problems in chickens (Butterworth et al., 2001) and it is increasingly reported in surgical site infections in small companion animals and horses (Catry et al., 2010).

\section{Methicillin-resistant Staphylococcus aureus (MRSA)}

Soon after the introduction of penicillin, around 1945, the majority of the $S$. aureus population had become resistant to penicillin through the production of beta-lactamase, an enzyme that hydrolyzes penicillin. In the late 1950s, the beta-lactamaseresistant methicillin was introduced in human medicine. However, soon after introduction, the first methicillin-resistant isolates of $S$. aureus were reported (Robinson and Enright, 2003).

Methicillin resistance is caused by the acquisition of the mecA gene. This gene encodes an alternative penicillin-binding protein, called PBP2A, which has a low affinity for beta-lactam antibiotics (Vanderhaeghen et al., 2010b). The mecA gene is part of a large mobile genetic element, the staphylococcal cassette chromosome 
mec ( $\mathrm{SCCmec).} \mathrm{SCCmec} \mathrm{can} \mathrm{be} \mathrm{integrated} \mathrm{at} \mathrm{a} \mathrm{specific} \mathrm{site} \mathrm{in} \mathrm{the}$ chromosome of methicillin-susceptible $S$. aureus (MSSA) which is located at the 3 prime end of an open reading frame of a gene with an unknown function (orfX) (Grundmann et al., 2006). SCCmec carries a set of cassette chromosome recombinase genes ( $c c r A, c c r B$ or $c c r C$ ) for excision and integration into the host chromosome. According to combinations of the mecA and ccr gene complexes contained by the bacterial genome, molecular typing of MRSA strains has revealed that eleven major SCCmec types and several subtypes and composites of two or more SCC elements have emerged worldwide (IWG-SCC, 2009). In addition to the difference in these gene complexes, the various SCCmec elements differ from each other in the antibiotic resistance markers to antimicrobials other than beta-lactams (Grundmann et al., 2006).

\section{Epidemiology of MRSA in Europe and definitions of MRSA groups}

The prevalence of MRSA infections in humans varies widely between European countries (Tiemersma et al., 2004). Especially in hospital settings MRSA occurrence is generally high in southern Europe where the proportion of MRSA among invasive (blood and liquor) S. aureus isolates up to $50 \%$ is documented (Fig. 1). In contrast, in northern Europe MRSA prevalence is very low, $<1 \%$, due to strict MRSA infection control policies (Tiemersma et al., 2004).

Traditionally MRSA has been considered a hospital-associated pathogen (HA-MRSA). Infections with HA-MRSA were supposed to be nosocomial if they emerged at least $48 \mathrm{~h}$ after admission. Prolonged hospital stay, care in intensive-care units, prolonged antibiotic treatment, surgical interventions and/or close contact with infected or colonized MRSA-positive individuals are risk factors for attracting HA-MRSA (McCarthy et al., 2010).

Until the 1990s, infections with MRSA were rarely observed in extramural communities. However, since the mid 1990s, MRSA strains were increasingly documented in healthy people without healthcare-associated risk factors. These cases were referred as community-associated MRSA (CA-MRSA). Close contact between humans in sport settings, schools, day-care centers, the military and prisons are considered to be risk factors (Catry et al., 2010). Analysis of the genetic background of these CA-MRSA strains has shown a clear distinction from typical HAMRSA. CA-MRSA and HA-MRSA belong to different sequence types and in addition carry different SCCmec types. Furthermore the carriage of virulence factors such as Panton-Valentine leukocidin (PVL) is merely associated with CA-MRSA strains (Vanderhaeghen et al., 2010b).

Recently, MRSA has been found to be emerging in livestock (Kock et al., 2010). Animals can act as reservoirs of MRSA, and the bacterium can be transmitted to humans in close contact with MRSA colonized animals. MRSA from this reservoir has been referred to as Livestock Associated-MRSA (LA-MRSA), to distinguish it from HA-MRSA and CA-MRSA types (Smith and Pearson, 2010).

\section{MRSA control in humans}

The large MRSA prevalence differences between countries can partly be explained by differences in level of screening, isolation and treatment of patients and staff in hospitals. For example, in the Netherlands and Scandinavian countries a pro-active system has been applied, called the "search and destroy" policy. This strategy consists of active screening of high-risk patients and exposed healthcare workers for MRSA carriage. Risk patients involved hospitalized patients who are repatriated from countries with high MRSA rates and contacts of MRSA patients (Kluytmans and Struelens, 2009). People who have had contact with live pigs or veal calves, were included to the risk group since July 2006 and November 2007, respectively (Vandenbroucke-Grauls and Beaujean, 2006). Strict implementation of transmission prevention measures for these risk groups and treatment of carriage using topical application of mupirocin nasal cream and washing with disinfecting

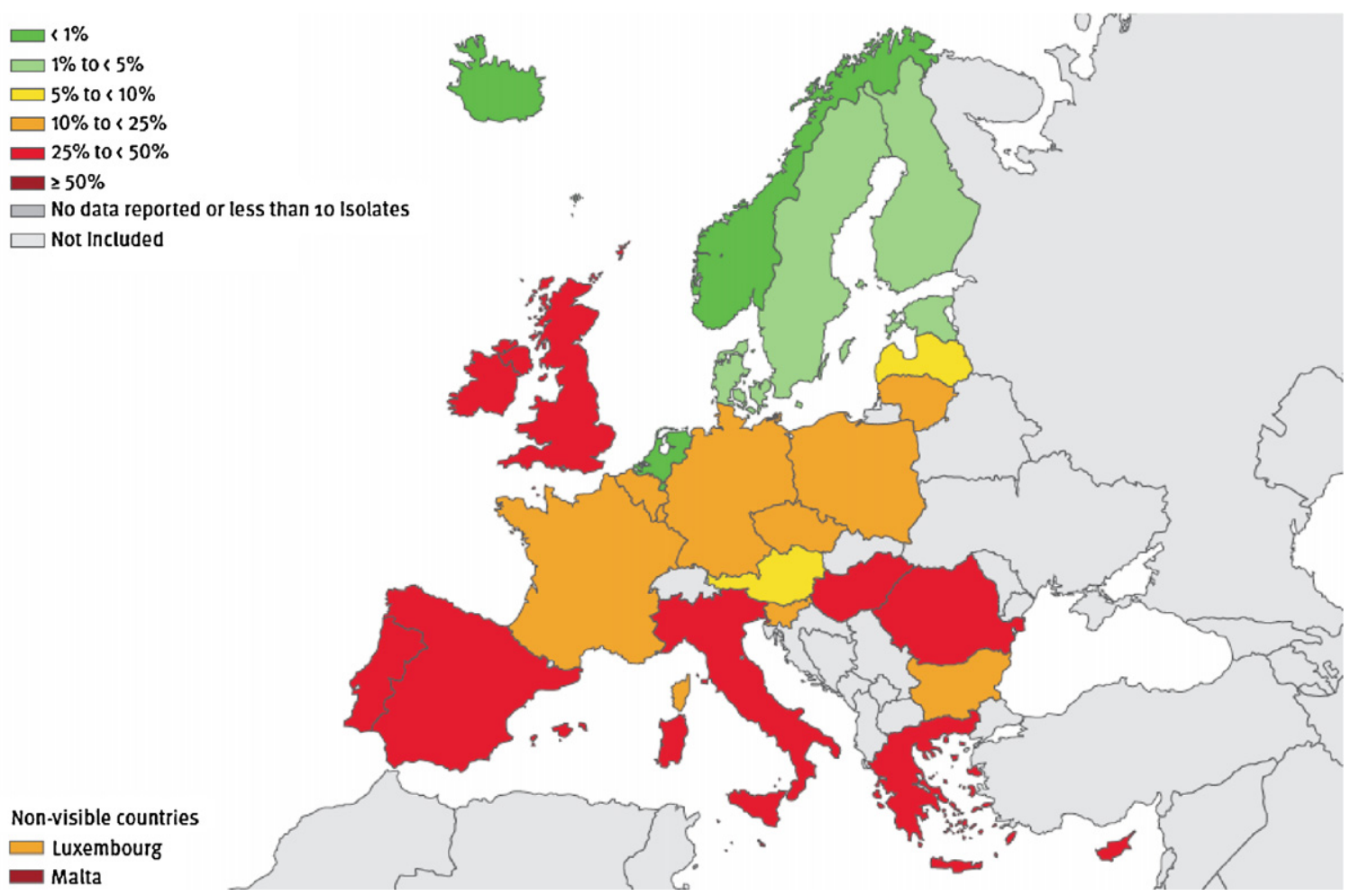

Fig. 1. MRSA prevalence among clinical invasive isolates in Europe in 2009 (European Antimicrobial Resistance Surveillance System) EARSS data. Available at: http://www.ecdc.europa.eu/en/publications/Publications/1011_SUR_annual_EARS_Net_2009.pdf (data retrieved on 8 August 2011). 
agents, such as chlorhexidine is part of the "search and destroy policy" (Kluytmans and Struelens, 2009). The full Dutch strategy is described in the national guidelines (www.wip.nl). In addition, the restrictive use of antimicrobials in humans in the Netherlands contributes to the low MRSA prevalence in the general population (Coenen et al., 2009).

\section{Emergence of LA-MRSA in livestock and other animals}

From 1970 to 2000, MRSA was rarely isolated from animals, and if so, these strains were generally supposed to be of human origin, as shown by bio-typing. Therefore, it was thought that until the end of the 20th century, the animal husbandry reservoir was of little relevance to MRSA causing diseases in humans. It was assumed that MRSA was a problem caused by antimicrobial use in human medicine (Catry et al., 2010).

In 1975 the first report on MRSA isolated from cows with mastitis was published (Devriese and Hommez, 1975). This sporadic case was followed by only a few other cases in the next 25 years. From 2000s onwards reports became more frequent and in 2007 transmission of MRSA (ST1; spa-type t127) between cows and humans was reported (Juhasz-Kaszanyitzky et al., 2007). The initial case of LA-MRSA in a human was described in 2005 in a 6 -month-old girl admitted to a hospital for invasive surgery in the Netherlands. The girl remained MRSA positive despite several decolonization attempts. The girl's parents, who lived on a swine farm, were also found to be colonized with MRSA (Voss et al., 2005). Since neither the girl nor her family had a history of traveling or admission to a foreign hospital and the MRSA-isolate was non-typeable by standard pulsed-field gel electrophoresis (PFGE), further investigations began into the source of the MRSA in regional pigs and pig farmers (Huijsdens et al., 2006). An additionally study on the presence of MRSA in pigs at slaughterhouse confirmed that LA-MRSA are widely spread in the Dutch pig population (de Neeling et al., 2007).

Genotyping showed that the LA-MRSA strains as found in pigs and pig farmers were non-typeable by PFGE as these were resistant to digestion with the routinely used enzyme Smal, and therefore referred to as non-typeable MRSA(NT-MRSA). Later studies showed that these isolates are typeable if another enzyme is used (Argudín et al., 2010). The strains belonged to clonal complex, CC398, with the majority of strains belonging to ST398. Risk factors for humans acquiring this LA-MRSA were pig and cattle farming (van Loo et al., 2007). From 2005 onwards LA-MRSA is more frequently reported in different food production animals including cattle (Vanderhaeghen et al., 2010a), pigs (Huijsdens et al., 2006; van Duijkeren et al., 2008) and poultry (Nemati et al., 2008; Mulders et al., 2010), also in other European countries outside the Netherlands (Lewis et al., 2008) as well as in the Americas (Smith et al., 2009) and Asia (Guardabassi et al., 2009; Wagenaar et al., 2009). The EU-baseline study on MRSA prevalence in swine production showed that in most European countries MRSA can be found on pig farms (European Food Safety Authority, 2009). In contrast to studies in Europe and the Americas, ST398 does not appear to be the dominant MRSA strain in Asian pigs. Several studies have shown that the predominant strain as found in Asian pigs belonged to ST9 (Cui et al., 2009; Guardabassi et al., 2009; Wagenaar et al., 2009). ST72 is the predominant MLST type found in meat products in Korea (Lim et al., 2010; Ko et al., 2011).

MRSA has also been found in companion animals, but these strains generally differ from those in livestock. The reason for this is that the transmission route is thought to be from humans to companion animals and therefore human epidemic clones are found in these animal species, i.e., MRSA in companion animals is primarily a humanosis (Morgan, 2008).

\section{Molecular aspects of MRSA ST398}

MRSA isolates of ST398 possess some typical features. As aforementioned, the strains are non-typeable with standard PFGE using Smal digestion. This is due to the presence of a restriction/methylation system leading to protection from Smal digestion (Bens et al., 2006). The strains carry SCCmec element IV or V (Smith and Pearson, 2010). SCCmec cassette types II and III have also been reported but this may be the result of misidentification (Jansen et al., 2009). Many different spa-types have been documented in ST398. In 2010 there were 25 different spa-types identified related to ST398 but new spa-types are continuously being reported (Vanderhaeghen et al., 2010b). It is suggested that ST398 has been evolved by multiple introductions of the SCCmec element. Studies have shown that strains with identical spa-types can carry different SCCmec elements (van Duijkeren et al., 2008). It has been suggested that coagulase-negative staphylococci in the farming environment could serve as a source of SCCmec (Hanssen and Ericson, 2006).

The transfer of staphylococcal toxin genes to isolates of CC398 seems to be uncommon (Smith and Pearson, 2010). Generally, certain important virulence factors (for instance Panton-Valentine Leukocidin (PVL), tst and LukM) are absent (Vanderhaeghen et al., 2010b). Despite the lack of these virulence factors, MRSA ST398 strains have been found to cause disease in both animals (van Duijkeren et al., 2007; Cuny et al., 2008; Vanderhaeghen et al., 2010a) and humans (Ekkelenkamp et al., 2006; Pan et al., 2009).

ST398 strains are generally resistant to tetracycline, and resistance against macrolides, lincosamides, aminoglycosides and trimethoprim is documented. Fluoroquinolone resistance has also been reported; though to a lesser extent (Vanderhaeghen et al., 2010b).

\section{Public health consequences of LA-MRSA}

Persons in direct contact with MRSA-positive animals have an increased risk of becoming MRSA positive. This has been documented for individuals working in companion animal and equine clinics, and livestock production environments (Morgan, 2008). It has been shown that MRSA ST398 has limited host specificity; it is able to colonize and to cause infections in various hosts. So far, the mechanisms of host adaptation are poorly understood (Cuny et al., 2010). However, incidentally reported so far, MRSA ST398 can cause serious (invasive) infections and outbreaks (Kluytmans, 2010).

There is a potential risk of MRSA introduction from the animal reservoir into hospitals with humans as vector. Therefore, in the Netherlands, pig and cattle farmers were included as risk groups as defined by the "Search and Destroy" policy. Consequently the annual number of people at submission to the hospital, suspected of MRSA colonization and requiring MRSA screening, has increased in the Netherlands due to the emergence of LA-MRSA. This is a huge burden for the health care system (van Rijen et al., 2008; Wassenberg and Bonten, 2010). Identification of risk factors and knowledge about persistence of LA-MRSA in humans is essential for successful continuation of the "Search and Destroy" policy. Improved understanding of the mechanisms underlying transmission and persistence, and the role of exposure in LA-MRSA carriage in both animals and humans could have a significant impact on antibiotic and infection control policies in the hospitals. It also provides information for evidence-based guidance on the development of new strategies and preventive measures for the control of MRSA. 


\section{Risk factors for animal and human LA-MRSA carriage}

Few studies investigated risk factors for the occurrence of ST398 in animals and humans. A high risk of animal to human transmission of ST398 has been reported in pig farming (Lewis et al., 2008; Smith et al., 2009; van den Broek et al., 2009). A direct association between MRSA carriage in animals and MRSA carriage in humans was observed in veal calf farming (Graveland et al., 2010). It was demonstrated that LA-MRSA carriage among veal farmers and their family members and employees was strongly associated with intensity of animal contact and with the number of MRSA-positive animals on the farm. However, a positive farmer clearly contributed to the risk of MRSA carriage in family members. On the other hand, a longitudinal study among farmers, employees and family members over a 10-week period showed that persistent carriers of ST398 were rarely observed. MRSA prevalence rapidly decreased during absence of animal contact, during holidays and in between production cycles, which suggests that LA-MRSA is a poor persistent colonizer in most humans (Graveland et al., 2011). The observed decrease in prevalence was strongest during the holiday period.

Veterinarians occupationally exposed to pigs also are at increased risk for becoming MRSA carriers (Wulf et al., 2008).

In human medicine, a causal relationship between the usage of antimicrobials and the presence of MRSA has been demonstrated (Tacconelli et al., 2008). It is hypothesized that a similar relationship may occur in animals (de Neeling et al., 2007; Wulf and Voss, 2008). In pig farming the use of standard antimicrobial medication of the pigs seems to be a risk factor for MRSA carriage (van Duijkeren et al., 2008). In veal farming, it is shown that calves were more often found MRSA positive when they had been treated with antibiotics (Graveland et al., 2010). However, further quantification is necessary. Farm hygiene appeared to be associated with a lower prevalence of MRSA among veal calves (Graveland et al., 2010).

\section{Human to human transmission of MRSA ST398}

Few studies have examined transmissibility, and from these it appears that in hospital settings, ST398 transmits less frequently than most HA-MRSA strains (van Rijen et al., 2008, 2009; Wassenberg and Bonten, 2010; Wassenberg et al., 2011). A large Dutch multi-center study in hospital settings has shown that the relative risk on transmission of MRSA ST398, as compared to HAMRSA, was 0.28 (Wassenberg et al., 2011). Based on these data, the genotype-specific single admission reproduction number $\left(R_{\mathrm{A}}\right.$ value) was estimated. For LA-MRSA this was 0.16 which is clearly lower than 0.93 as found for HA-MRSA. Taken these $R_{\mathrm{A}}$ values together, this resulted in a $R_{\mathrm{A}}$ ratio between HA-MRSA and LAMRSA of 5.9 (95\% CI 2.24-23.81), indicating that LA-MRSA is 5.9 times less transmissible than HA-MRSA (Bootsma et al., 2011). However, these data should be interpreted with caution since several assumptions about homogeneity between HA-MRSA and LA-MRSA carriers are made and data of other potential risk factors and patient characteristics are lacking or ignored in these calculations. Despite the lower human to human transmission likelihood of LA-MRSA, a positive association between MRSA carrier status of family members and MRSA carriage of the farmer was demonstrated in veal farming (Graveland et al., 2011). Especially this finding in children, suggests that MRSA carriage in children, who are generally low exposed, is more strongly determined by contact with highly exposed family members or through environmental contamination than by direct animal contact.

Generally, transmission is dependent of host and environmental characteristics. This explains why differences may occur in human to human transmission in and outside hospital settings. This is also recognized by Wassenberg et al. (2011), who mention that farmers usually belong to a healthy population (as compared to hospitalized patients with non-ST398 MRSA) and they therefore, in hospital settings, may be less likely to transmit the pathogen to other patients. Despite the fact that the risk for transmission in clinical populations is considerably lower for ST398, public health aspects of ST398 carriage, and rapid emergence in livestock and human populations closely associated with livestock, require further attention.

\section{Conclusions}

LA-MRSA seems to be recently introduced into production animals and is predominantly present in pigs and veal calves. However other animals can be MRSA carrier as well due to overflow towards other species.

It has been shown that persons in direct (occupational) contact to LA-MRSA-positive animals have an increased risk for LA-MRSA carriage. The risk for LA-MRSA carriage in humans is mainly related to exposure to MRSA-positive animals. However, the positive association between MRSA carrier status of family members and MRSA carriage of the farmer indicates that human to human transmission cannot be excluded. It has been shown that MRSA ST398 has limited host specificity; it is able to colonize and to cause infections in various hosts.

Farm hygiene (cleaning and disinfection of stables between production cycles) seems to be associated with a lower prevalence of MRSA. Antimicrobial use contributes to MRSA presence in animals. These two determinants of ST398 MRSA may be incorporated into control programmes aiming for a reduction of MRSA in livestock.

Like any other microorganism, LA-MRSA is expected to be able to adapt to new hosts and may change over time in the potential to colonize and to produce toxins. Also, the current circulating clone CC398 may be replaced by another clone in Western countries or emerge in countries where this clone is currently low-prevalent. Ongoing MRSA surveillance in humans and animals is needed to detect changes in epidemiology and to implement effective control measures.

\section{References}

Argudín, M.A., Rodicio, M.R., Guerra, B., 2010. The emerging methicillin-resistant Staphylococcus aureus ST398 clone can easily be typed using the Cfr9I SmaIneoschizomer. Lett. Appl. Microbiol. 50, 127-130.

Bens, C.C., Voss, A., Klaassen, C.H., 2006. Presence of a novel DNA methylation enzyme in methicillin-resistant Staphylococcus aureus isolates associated with pig farming leads to uninterpretable results in standard pulsed-field gel electrophoresis analysis. J. Clin. Microbiol. 44, 1875-1876.

Bootsma, M.C., Wassenberg, M.W., Trapman, P., Bonten, M.J., 2011. The nosocomial transmission rate of animal-associated ST398 meticillin-resistant Staphylococcus aureus. J. R. Soc. Interface 8, 578-584.

Butterworth, A., Reeves, N.A., Harbour, D., Werrett, G., Kestin, S.C., 2001. Molecular typing of strains of Staphylococcus aureus isolated from bone and joint lesions in lame broilers by random amplification of polymorphic DNA. Poult. Sci. 80, 1339-1343.

Catry, B., Van Duijkeren, E., Pomba, M.C., Greko, C., Moreno, M.A., Pyorala, S., Ruzauskas, M., Sanders, P., Threlfall, E.J., Ungemach, F., Torneke, K., MunozMadero, C., Torren-Edo, J., Scientific Advisory Group on Antimicrobials (SAGAM), 2010. Reflection paper on MRSA in food-producing and companion animals: epidemiology and control options for human and animal health. Epidemiol. Infect. 138, 626-644.

Coenen, S., Muller, A., Adriaenssens, N., Vankerckhoven, V., Hendrickx, E., Goossens, H., ESAC Project Group, 2009. European surveillance of antimicrobial consumption (ESAC): outpatient parenteral antibiotic treatment in Europe. J. Antimicrob. Chemother. 64, 200-205.

Cui, S., Li, J., Hu, C., Jin, S., Li, F., Guo, Y., Ran, L., Ma, Y., 2009. Isolation and characterization of methicillin-resistant Staphylococcus aureus from swine and workers in china. J. Antimicrob. Chemother. 64, 680-683.

Cuny, C., Friedrich, A., Kozytska, S., Layer, F., Nubel, U., Ohlsen, K., Strommenger, B., Walther, B., Wieler, L., Witte, W., 2010. Emergence of methicillin-resistant Staphylococcus aureus (MRSA) in different animal species. Int. J. Med. Microbiol. 300, 109-117.

Cuny, C., Strommenger, B., Witte, W., Stanek, C., 2008. Clusters of infections in horses with MRSA ST1 ST254, and ST398 in a veterinary hospital. Microb. Drug Resist. 14, 307-310 
de Neeling, A.J., van den Broek, M.J., Spalburg, E.C., van Santen-Verheuvel, M.G., DamDeisz, W.D., Boshuizen, H.C., van de Giessen, A.W., van Duijkeren, E., Huijsdens, X.W., 2007. High prevalence of methicillin resistant Staphylococcus aureus in pigs. Vet. Microbiol. 122, 366-372.

Devriese, L.A., Hommez, J., 1975. Epidemiology of methicillin-resistant Staphylococcus aureus in dairy herds. Res. Vet. Sci. 19, 23-27.

European Food Safety Authority, 2009. Analysis of the baseline survey on the prevalence of methicillin-resistant Staphylococcus aureus (MRSA) in holdings with breeding pigs, in the EU, 2008 [1]-Part A: MRSA prevalence estimates. EFSA J. 7 (1376), 82.

Ekkelenkamp, M.B., Sekkat, M., Carpaij, N., Troelstra, A., Bonten, M.J., 2006. Endocarditis due to meticillin-resistant Staphylococcus aureus originating from pigs. Ned. Tijdschr. Geneeskd. 150, 2442-2447.

Graveland, H., Wagenaar, J.A., Bergs, K., Heesterbeek, H., Heederik, D., 2011. Persistence of livestock associated MRSA CC398 in humans is dependent on intensity of animal contact. PLoS One 6, e16830.

Graveland, H., Wagenaar, J.A., Heesterbeek, H., Mevius, D., van Duijkeren, E., Heederik, D., 2010. Methicillin resistant Staphylococcus aureus ST398 in veal calf farming: Human MRSA carriage related with animal antimicrobial usage and farm hygiene. PLoS One 5, e10990.

Grundmann, H., Aires-de-Sousa, M., Boyce, J., Tiemersma, E., 2006. Emergence and resurgence of meticillin-resistant Staphylococcus aureus as a public-health threat. Lancet 368, 874-885.

Guardabassi, L., O’Donoghue, M., Moodley, A., Ho, J., Boost, M., 2009. Novel lineage of methicillin-resistant Staphylococcus aureus, Hong Kong. Emerg. Infect. Dis. 15, 1998-2000.

Hanssen, A.M., Ericson, J.U., 2006. SCCmec in staphylococci: genes on the move. FEMS Immunol. Med. Microbiol. 46, 8-20.

Huijsdens, X.W., van Dijke, B.J., Spalburg, E., van Santen-Verheuvel, M.G., Heck, M.E., Pluister, G.N., Voss, A., Wannet, W.J., de Neeling, A.J., 2006. Community-acquired MRSA and pig-farming. Ann. Clin. Microbiol. Antimicrob. 5, 26.

International Working Group on the Classification of Staphylococcal Cassette Chromosome Elements (IWG-SCC), 2009. Classification of staphylococcal cassette chromosome mec (SCCmec): guidelines for reporting novel SCCmec elements. Antimicrob. Agents Chemother 53, 4961-4967.

Jansen, M.D., Box, A.T., Fluit, A.C., 2009. SCCmec typing in methicillin-resistant Staphylococcus aureus strains of animal origin. Emerg. Infect. Dis. 15, 136-137, author reply.

Juhasz-Kaszanyitzky, E., Janosi, S., Somogyi, P., Dan, A., van der Graaf-van Bloois, L., van Duijkeren, E., Wagenaar, J.A., 2007. MRSA transmission between cows and humans. Emerg. Infect. Dis. 13, 630-632.

Kluytmans, J., Struelens, M., 2009. Meticillin resistant Staphylococcus aureus in the hospital. BMJ 338, b364

Kluytmans, J.A., 2010. Methicillin-resistant Staphylococcus aureus in food products: cause for concern or case for complacency? Clin. Microbiol. Infect. 16, 11-15.

Ko, K.S., Lim, S.K., Jung, S.C., Yoon, J.M., Choi, J.Y., Song, J.H., 2011. Sequence type 72 meticillin-resistant Staphylococcus aureus isolates from humans, raw meat and soil in South Korea. J. Med. Microbiol. 60, 442-445.

Kock, R., Becker, K., Cookson, B., van Gemert-Pijnen, J.E., Harbarth, S., Kluytmans, J., Mielke, M., Peters, G., Skov, R.L., Struelens, M.J., Tacconelli, E., Navarro Torne A., Witte, W., Friedrich, A.W., 2010. Methicillin-resistant Staphylococcus aureus (MRSA): burden of disease and control challenges in Europe. Euro Surveill. 15 19688.

Lewis, H.C., Molbak, K., Reese, C., Aarestrup, F.M., Selchau, M., Sorum, M., Skov, R.L., 2008. Pigs as source of methicillin-resistant Staphylococcus aureus CC398 infections in humans, Denmark. Emerg. Infect. Dis. 14, 1383-1389.

Lim, S.K., Nam, H.M., Park, H.J., Lee, H.S., Choi, M.J., Jung, S.C., Lee, J.Y., Kim, Y.C., Song, S.W., Wee, S.H., 2010. Prevalence and characterization of methicillinresistant Staphylococcus aureus in raw meat in Korea. J. Microbiol. Biotechnol. 20, 775-778.

Lowy, F.D. 1998. Staphylococcus aureus infections. N. Engl. J. Med. 339, 520-532.

McCarthy, N.L., Sullivan, P.S., Gaynes, R., Rimland, D., 2010. Health care-associated and community-associated methicillin-resistant Staphylococcus aureus infections: a comparison of definitions. Am. J. Infect. Control 38, 600-606.

Morgan, M., 2008. Methicillin-resistant Staphylococcus aureus and animals: Zoonosis or humanosis? J. Antimicrob. Chemother. 62, 1181-1187.

Mulders, M.N., Haenen, A.P., Geenen, P.L., Vesseur, P.C., Poldervaart, E.S., Bosch, T., Huijsdens, X.W., Hengeveld, P.D., Dam-Deisz, W.D., Graat, E.A., Mevius, D. Voss, A., Van De Giessen, A.W., 2010. Prevalence of livestock-associated MRSA in broiler flocks and risk factors for slaughterhouse personnel in the Netherlands. Epidemiol. Infect. 138, 743-755.

Nemati, M., Hermans, K., Lipinska, U., Denis, O., Deplano, A., Struelens, M. Devriese, L.A., Pasmans, F., Haesebrouck, F., 2008. Antimicrobial resistance of old and recent Staphylococcus aureus isolates from poultry: first detection of livestock-associated methicillin-resistant strain ST398. Antimicrob. Agents Chemother. 52, 3817-3819.

Pan, A., Battisti, A., Zoncada, A., Bernieri, F., Boldini, M., Franco, A., Giorgi, M. lurescia, M., Lorenzotti, S., Martinotti, M., Monaci, M., Pantosti, A., 2009. Community-acquired methicillin-resistant Staphylococcus aureus ST398 infection, Italy. Emerg. Infect. Dis. 15, 845-847.

Robinson, D.A., Enright, M.C., 2003. Evolutionary models of the emergence of methicillin-resistant Staphylococcus aureus. Antimicrob. Agents Chemother. 47 3926-3934.

Smith, T.C., Male, M.J., Harper, A.L., Kroeger, J.S., Tinkler, G.P., Moritz, E.D., Capuano, A.W., Herwaldt, L.A., Diekema, D.J., 2009. Methicillin-resistant Staphylococcus aureus (MRSA) strain ST398 is present in Midwestern U.S. Swine and Swine workers. PLoS One 4, e4258.

Smith, T.C., Pearson, N., 2010. The emergence of Staphylococcus aureus ST398. Vector Borne Zoonotic Dis.

Tacconelli, E., De Angelis, G., Cataldo, M.A., Pozzi, E., Cauda, R., 2008. Does antibiotic exposure increase the risk of methicillin-resistant Staphylococcus aureus (MRSA) isolation? A systematic review and meta-analysis. J. Antimicrob. Chemother. 61, 26-38.

Tiemersma, E.W., Bronzwaer, S.L., Lyytikainen, O., Degener, J.E., Schrijnemakers, P., Bruinsma, N., Monen, J., Witte, W., Grundman, H., 2004. European antimicrobial resistance surveillance system participants methicillin-resistant Staphylococcus aureus in Europe, 1999-2002. Emerg. Infect. Dis. 10, 1627-1634.

van den Broek, I.V., Van Cleef, B.A., Haenen, A., Broens, E.M., Van der Wolf, P.J., Van den Broek, M.J., Huijsdens, X.W., Kluytmans, J.A., Van DE Giessen, A.W., Tiemersma, E.W., 2009. Methicillin-resistant Staphylococcus aureus in people living and working in pig farms. Epidemiol. Infect. 137, 700-708.

van Duijkeren, E., Ikawaty, R., Broekhuizen-Stins, M.J., Jansen, M.D., Spalburg, E.C., de Neeling, A.J., Allaart, J.G., van Nes, A., Wagenaar, J.A., Fluit, A.C., 2008. Transmission of methicillin-resistant Staphylococcus aureus strains between different kinds of pig farms. Vet. Microbiol. 126, 383-389.

van Duijkeren, E., Jansen, M.D., Flemming, S.C., de Neeling, H., Wagenaar, J.A., Schoormans, A.H., van Nes, A., Fluit, A.C., 2007. Methicillin-resistant Staphylococcus aureus in pigs with exudative epidermitis. Emerg. Infect. Dis. 13, 1408-1410.

van Loo, I., Huijsdens, X., Tiemersma, E., de Neeling, A., van de Sande-Bruinsma, N., Beaujean, D., Voss, A., Kluytmans, J., 2007. Emergence of methicillin-resistant Staphylococcus aureus of animal origin in humans. Emerg. Infect. Dis. 13, 1834-1839.

van Rijen, M.M., Bosch, T., Heck, M.E., Kluytmans, J.A., 2009. Meticillin-resistant Staphylococcus aureus epidemiology and transmission in a Dutch hospital. J. Hosp. Infect. 72, 299-306.

van Rijen, M.M., Van Keulen, P.H., Kluytmans, J.A., 2008. Increase in a Dutch hospital of methicillin-resistant Staphylococcus aureus related to animal farming. Clin. Infect. Dis. 46, 261-263.

Vandenbroucke-Grauls, C.M., Beaujean, D.J., 2006. Methicillin-resistant Staphylococcus aureus in pig breeders and cattle breeders. Ned. Tijdschr. Geneeskd. 150 $1710-1712$.

Vanderhaeghen, W., Cerpentier, T., Adriaensen, C., Vicca, J., Hermans, K., Butaye, P., 2010a. Methicillin-resistant Staphylococcus aureus (MRSA) ST398 associated with clinical and subclinical mastitis in Belgian cows. Vet. Microbiol. 144, 166-171.

Vanderhaeghen, W., Hermans, K., Haesebrouck, F., Butaye, P., 2010b. Methicillinresistant Staphylococcus aureus (MRSA) in food production animals. Epidemiol. Infect. 138, 606-625.

Voss, A., Loeffen, F., Bakker, J., Klaassen, C., Wulf, M., 2005. Methicillin-resistant Staphylococcus aureus in pig farming. Emerg. Infect. Dis. 11, 1965-1966.

Wagenaar, J.A., Yue, H., Pritchard, J., Broekhuizen-Stins, M., Huijsdens, X., Mevius, D.J., Bosch, T., Van Duijkeren, E., 2009. Unexpected sequence types in livestock associated methicillin-resistant Staphylococcus aureus (MRSA): MRSA ST9 and a single locus variant of ST9 in pig farming in china. Vet. Microbiol. 139, 405-409.

Wassenberg, M.W., Bonten, M.J., 2010. The Dutch MRSA policy can and should be different. Ned. Tijdschr. Geneeskd. 154, A2575.

Wassenberg, M.W., Bootsma, M.C., Troelstra, A., Kluytmans, J.A., Bonten, M.J., 2011. Transmissibility of livestock-associated methicillin-resistant Staphylococcus aureus (ST398) in Dutch hospitals. Clin. Microbiol. Infect. 17, 316-319.

Wertheim, H.F., Melles, D.C., Vos, M.C., van Leeuwen, W., van Belkum, A., Verbrugh H.A., Nouwen, J.L., 2005. The role of nasal carriage in Staphylococcus aureus infections. Lancet Infect. Dis. 5, 751-762.

Wulf, M., Voss, A., 2008. MRSA in livestock animals-an epidemic waiting to happen? Clin. Microbiol. Infect. 14,519-521.

Wulf, M.W., Sørum, M., van Nes, A., Skov, R., Melchers, W.J., Klaassen, C.H., Voss, A. 2008. Prevalence of methicillin-resistant Staphylococcus aureus among veterinarians: an international study. Clin. Microbiol. Infect. 14, 29-34. 